\title{
Compatibility of Elastomers in Biodiesel-diesel-bioethanol Blend (BDE)
}

\author{
S.K.Thangavelu 1, 3, a , C. Piraiarasi ${ }^{1, b}$, A. S. Ahmed ${ }^{2, c}$, F.N. Ani ${ }^{3, d}$ \\ ${ }^{1}$ Faculty of Engineering, Computing and Science, Swinburne University of Technology, Kuching, \\ Sarawak, Malaysia \\ ${ }^{2}$ Department of Mechanical and Manufacturing Engineering, Faculty of Engineering, Universiti \\ Malaysia Sarawak, Sarawak, Malaysia \\ ${ }^{3}$ Faculty of Mechanical Engineering, Universiti Teknologi Malaysia, Skudai, Johor D.T., Malaysia \\ a sthangavelu@swinburne.edu.my, ${ }^{\mathrm{b}}$ pchelladorai@swinburne.edu.my, ${ }^{\mathrm{c}}$ aasaleh@feng.unimas.my, \\ farid@fkm.utm.my
}

Keywords: Degradation, Elastomers, Palm biodiesel, Diesel, Bioethanol

\begin{abstract}
The present study aims to investigate the impact of biodiesel-diesel-bioethanol (BDE) blended fuel on the degradation behavior of elastomers such as nitrile rubber (NBR) and polytetrafluroethylene (PTFE). Static immersion test in B20D75E5 blends (20\% biodiesel, 75\% diesel and $5 \%$ bioethanol) at $50^{\circ} \mathrm{C}$ for $200 \mathrm{~h}$ was carried out. At the end of immersion test, degradation behaviour of elastomers was investigated by measuring mass, volume and hardness. The exposed surface of elastomers was studied using optical microscope (OM). Fourier Transform Infrared (FTIR) spectroscopy was carried out to identify the chemical and structural changes in the elastomers. Moreover, physical and chemical characteristics of the fuel blend after the immersion test such as total acid number (TAN), density and colour change were also investigated. Results showed that the degradation of NBR was high compared to PTFE.
\end{abstract}

\section{Introduction}

In recent days, the depletion of fossil fuel and the environmental pollution are driving the search for new alternative fuels. Biofuels (bioethanol and biodiesel) have gained progressive importance as alternative fuel for automobile engines [1]. Biodiesel is produced by transesterification of vegetable oils or animal fats. It offers properties close to that of diesel fuel and has no sulfur or aromatics [2]. Bioethanol represents an important biofuel produced from biomass and bioenergy crops to replace the use of fossil fuels in both diesel and gasoline engine [3, 4]. Biodiesel is miscible with alcohols and diesel; it can also be used as an emulsifier to blend alcohols and diesel and to be used as biodiesel-alcohol-diesel blends in diesel engines [5]. Studies regarding the mixing stability and fuel properties of biodiesel-ethanol-diesel fuels show that the addition of biodiesel prevented phase separation and its high cetane number improved the low cetane number of diesel-ethanol blended fuels [6]. Ethanol blended fuels reduced NO emissions for all concentrations while unburned HC emissions depended [7]. Labeckas et al. [6] suggested that ethanol up to $15 \mathrm{vol} \%$ blend could be efficiently used for diesel engine together with the biodiesel and diesel blend. Moreover, the simultaneous addition of anhydrous ethanol and methyl ester to commercial diesel fuel suggest ecological advantages and increases the renewable biofuel concentration in the blend. In diesel engine, fuel comes into contact with a wide variety of materials. Material compatibility with biodiesel is different from that of diesel. Diesel is a mixture of hydrocarbons, while biodiesel is a mixture of fatty acid esters [2]. The compatibility of seal, gaskets, hose materials that are commonly used in automotive fuel systems with conventional diesel fuel has long been established [8]. It has been reported that degradation of certain elastomers is one of the main issues related to material incompatibility in biodiesel [9]. Elastomers as one of the most important groups of materials, used in fuel system are of particular concern. This is because the elastomers are vulnerable to attack by various chemicals and can undergo degradation of their physical properties and stability [10]. Recently, Haseeb et al. [11] investigated the impact of palm biodiesel on the degradation behavior of 